This is an Accepted Manuscript of an article published by Taylor \& Francis Group in Managing Sport and

Leisure on 02 May 2019, available online: http://www.tandfonline.com/10.1080/23750472.2019.1612269.

\title{
A Stakeholder Approach to Performance Management in Botswana National Sport
}

\section{Organisations}

Lobone Kasale, Mathieu Winand, and Stephen Morrow - University of Stirling

\begin{abstract}
Rationale: Performance management is important to National Sport Organisations because it aims to ensure their transparency, accountability and offers an opportunity for improved service delivery to stakeholders. However, the role played by stakeholders in how performance management systems are used by National Sport Organisations remains unclear. This study investigates how different stakeholders influence the implementation of performance management among National Sport Organisations.
\end{abstract}

Approach: The study was conducted in Botswana, a developing country in Southern Africa. A qualitative approach was used in this study and data was collected from 14 National Sport Organisations and their 10 stakeholders through semi structured interviews and focus groups. Findings: The results reveal that different stakeholders used influence strategies directly and indirectly to affect performance management stages including goal and objective setting, activities and processes, performance measurement, feedback and feedforward.

Practical implications: This study informs sport managers on how stakeholders use influence strategies on performance management processes, helping them to better manage their organisations and stakeholder relationships.

Research contribution: The study contributes to our understanding on how performance management processes are developed and shaped, and how multiple stakeholders influence internal processes within sport organisations.

Keywords: performance management, National Sport Organisations, influence strategies, stakeholder salience 


\section{Introduction}

The relationship between National Sport Organisations (NSOs) and their stakeholders, specifically how stakeholders influence organisational processes is crucial. Researchers have used a variety of approaches and different theoretical lenses to understand the influence of stakeholders on decision making (Heffernan \& O’Brien, 2010; Miragaia, Ferreira, \& Carreira, 2014; Parent \& Séguin, 2007), financial performance (Sotiriadou, 2009) and management structures (Holt, 2007) in NSOs. However, research that explores the influence of stakeholders on how NSOs implement performance management (PM) is still lacking.

NSOs are non-profit organisations that administer their sport and provide sport services to communities in their countries (Shilbury \& Moore, 2006). They have developed relationships with individuals, groups or other organisations - their stakeholders - that affect or are affected by their actions (Babiak, 2007). In some cases, NSOs depend on their stakeholders to provide resources such as grants, sponsorships, access to facilities and professional services (Wicker, Vos, Scheerder, \& Breuer, 2013). In return, stakeholders expect NSOs to be transparent, accountable and to build their capacity to meet stakeholder demands by managing their organisational performance (O’Boyle, 2015; Winand, Zintz, Bayle, \& Robinson, 2010). However, how different stakeholders influence PM of NSOs and the influence strategies that they use remains unknown.

Frooman (1999) has pointed out that most stakeholder research addresses managerial behaviour taken in response to stakeholders, rather than considering how the behaviour of the stakeholders affect organisations. Furthermore, Laplume, Sonpar and Litz (2008) suggested that managers should establish strategies that stakeholders are likely to use to influence organisations. Drawing on these views, the aim of this study is to establish how stakeholders 
influence the PM of NSOs. To pursue this aim, the objectives that guide the study are; to identify NSO stakeholders according to their salience using the power, urgency and legitimacy framework (Mitchell, Agle, \& Wood, 1997); and to identify influence strategies used by stakeholders to affect the implementation of PM among NSOs (Frooman, 1999). Using these complementary frameworks provides an opportunity to offer deeper insights on the influence of stakeholders on the PM of NSOs.

This study was conducted in Botswana, a developing Southern African country where research of this nature has not previously been conducted. Prior studies on organisational performance of NSOs have been conducted in countries including Australia (Shilbury \& Moore, 2006), Belgium (Winand, Rihoux, Robinson, \& Zintz, 2013; Winand et al., 2010), Canada (Chelladurai \& Haggerty, 1991), France, (Bayle \& Robinson, 2007), Greece (Papadimitriou \& Taylor, 2000), Portugal, Spain, Italy (Madella et al., 2005), New Zealand (O’Boyle \& Hassan, 2015) and Russia (Solntsev \& Osokin, 2018), where the countries' economies allow for bigger NSOs with numerous and more lucrative resource streams. Therefore, this study offers a distinct perspective into the operation of NSOs in a developing African country, a markedly different social, economic and cultural context than that experienced by NSOs in more developed countries.

In the next section of this paper, a review of literature on PM, stakeholder identification, influence strategies, and how stakeholders influence PM of NSOs is presented. Next the study methods are discussed, beginning with an overview of the geographical context and how it influenced the rationale for the chosen methods. The research design, including information on study participants, the phases of the data collection exercise and the data analysis processes are presented in the following methods section. The results are then presented according to topics 
that include stakeholder identification, types of NSO stakeholders, influence strategies used by NSO stakeholders and stakeholder influence on the PM process. In the section that follows, the discussion is structured around themes that include the salience of NSO stakeholders and stakeholder influence and PM. These thematic areas help to illuminate the link between the results, theoretical framework and insights from Botswana on how stakeholders influence PM of NSOs. The paper concludes with a summary of the conclusions drawn, the implications of the study and of how it contributes to sport management literature and practice.

\section{LITERATURE REVIEW}

Performance management is a process that provides a proactive closed loop control system where strategies are deployed to all organisational processes, and feedback is obtained through a performance measurement system to enable appropriate management decisions (Bititci, Carrie, \& McDevitt, 1997). It is a cyclic process made up of phases that include goals and objectives setting, organisational processes and activities, performance measurement, feedback and feedforward (Ferreira \& Otley, 2009). While PM can be used to improve the efficiency and effectiveness of organisational processes, it may be implemented differently by NSOs due to their stakeholders' influence on decision-making and organisational processes. To understand the influence of PM among NSOs, it is essential to identify who these stakeholders are, their level of influence and why they influence organisational decisions and processes. Identifying stakeholders and their level of influence begins the process of understanding how they are likely to impact the implementation of PM and to that end, how stakeholders are identified is presented in the next section.

\section{Stakeholder identification}


Freeman (1984: p 46) has described a stakeholder as "any group or individual who can affect or is affected by the achievement of an organisation's objectives". NSOs have multiple stakeholders that include International and Continental Federations, National Olympic Committees, government ministries responsible for sport, national sport agencies, sponsors, media, clubs, teams and individual members (Bayle \& Madella, 2002). These stakeholders play various roles necessary for the success of NSOs and in-turn expect their needs to be satisfied (Papadimitriou \& Taylor, 2000; Shilbury \& Moore, 2006). Thus, PM is crucial to improving the capacity of NSO processes, as they endeavour to satisfy their multiple stakeholders (O’Boyle \& Hassan, 2015).

Stakeholders have been identified and classified as: internal and external; primary and secondary; and voluntary and involuntary (Clarkson, 1995; Freeman, 1984; Olander, 2007). Internal stakeholders implement organisational projects while external stakeholders are affected by the project (Freeman 1984; Olander 2007). Voluntary stakeholders bear risk by investing capital on an organisation, while involuntary stakeholders are placed at risk by an organisation's activities (Clarkson, 1994). According to Clarkson (1995) an organisation cannot survive without the participation of primary stakeholders, while secondary stakeholders are those that affect or are affected by, but not engaged in, organisational activities.

Mitchell et al. (1997) developed a framework to identify and classify stakeholders according to their salience, described as the degree to which managers give priority to competing claims of stakeholders. Their framework uses power, legitimacy and urgency attributes and classifies stakeholders into categories that include definitive, dominant, dependent, dangerous, dormant, discretionary, demanding and non-stakeholders. While there are various approaches 
to identify and classify stakeholders, Mitchell et al.'s (1997) framework was considered appropriate for this study as it uses attributes that describe the claims that stakeholders place on organisations. Additionally, they use a variety of categories to classify stakeholders according to the number of attributes they possess, providing opportunities to classify the wide range of NSO stakeholders.

According to Mitchell et al. (1997: p 865) "a party to a relationship has power based on the extent to which they can gain access to coercive (physical resources of force, violence or restraint), utilitarian (material or financial resources) or normative (symbolic resources) means to impose their will in the relationship". Therefore, a stakeholder can impose their will on an organisation based on the power that they possess (Mitchell et al., 1997). Legitimacy on the other hand is an assumption that stakeholder actions are desirable and appropriate according to norms, values, beliefs and definitions of a social system (Mitchell et al., 1997). Urgency is the extent to which stakeholder claims are critical, time sensitive and call for immediate attention (Mitchell et al., 1997). The more a stakeholder possesses power, legitimacy and urgency attributes, the more salient they become. Mitchell et al. (1997) further noted that (1) the attributes were variable and not steady; (2) the attributes were socially constructed; and that (3) an individual or entity may not be conscious of possessing attributes or, if conscious may choose not to enact any implied behaviours.

Mitchell et al.'s (1997) framework has been widely used in sport management literature to identify stakeholders in football clubs (Anagnostopoulos, 2011; Miragaia et al., 2014) and organising committees bidding for international events (Hautbois, Parent \& Séguin 2012; Parent \& Deephouse, 2007). In their study, Parent and Deephouse (2007) supported the positive relationship between the number of attributes and salience, and further observed that 
the hierarchical level and role of managers had a direct and moderating effect on stakeholder identification and salience. Furthermore, Hautbois et al. (2012) established that stakeholder salience was context or case dependent, changing at different phases of the bidding process with some stakeholders gaining or losing attributes.

While these studies confirm the utility of Mitchell et al.'s (1997) framework in identifying salient stakeholders, Parent and Deephouse (2007) reported that stakeholder types could be more limited in practice than in theory. This suggests the need for further research to test the utility of this framework. Additionally, because this study establishes how different NSO stakeholders use influence strategies to affect PM processes based on their possession of power, legitimacy and urgency attributes, there is a need to explore influences strategies that stakeholders use on NSOs. These are discussed in the next section.

\section{Stakeholder influence strategies}

In a broad sense, stakeholder influence can be described as the level of stakeholder involvement in an organisation or the extent to which a stakeholder can compel others to follow a certain course of action (Eberendu, Akpana, Uban, \& Okorocha, 2017). Stakeholders have the capacity to influence decision-making and organisational processes and may employ various strategies to change organisational practices (Rowley \& Moldoveanu, 2003). A stakeholder can exert influence over an organisation in a situation where the organisation depends on that stakeholder for resources (De Bakker \& Den Hond, 2008). Hence, resource dependence theory provides a framework to explore the power, dependence, autonomy and constraint relationships between the NSO and its stakeholders. 
Resource dependence theory posits that organisations that are unable to generate resources internally, interact with other organisations within their environments to acquire the resources they need to operate (Pfeffer \& Salancik, 1978). While the resources received from the external environment reduces their financial vulnerability, their autonomy and ability to act independently is also greatly reduced because organisations that provide these critical resources have the power to influence the behaviour of the resource dependent organisation (Pfeffer \& Salancik, 1978; Wicker \& Breuer, 2011). The power to influence the behaviour of an organisation based on control over resources forms the foundation of the influence strategies that stakeholders use on focal organisations (Elijido-Ten, Kloot \& Clarkson, 2010; Frooman, 1999; Hendry, 2005).

Based on this principle, Frooman (1999) developed a model that uses levels of resource dependence to determine the power that stakeholders have, and how they use it to influence organisational and decision-making processes. The model describes influence strategies used by stakeholders and the ways in which these can manipulate the supply of resources to focal organisations. According to Frooman (1999) stakeholders can use withholding or usage strategies, directly or indirectly to influence the behaviour of organisations. Withholding strategies entail discontinuing the provision of resources to an organisation with the intention of encouraging that organisation to change aspects of its behaviour (Elijido-Ten et al., 2010; Frooman, 1999). These withholding strategies work when the organisation depends on stakeholders' resources and when the balance of power resides with the stakeholders (Frooman, 1999; Hendry, 2005). On the other hand, stakeholders adopt usage strategies when the organisation does not depend on them and they stand to lose if they discontinued their provision of resources (Frooman, 1999; Tsai, Yeh, Wu, \& Huang, 2005). In other words, when the balance of power is evenly distributed between stakeholder and the focal 
organisation, stakeholders will continue to provide resources to the organisation with conditions attached (Frooman, 1999; Hendry, 2005).

Stakeholders can use either direct or indirect pathways to manipulate the flow of resources to an organisation (Frooman, 1999). Direct pathways are used when stakeholders manipulate the flow of resources to the organisation through either withholding or usage strategies, whereas for indirect pathways, stakeholders work with allies to manipulate the flow of resources to the organisation through withholding and usage. Furthermore, Frooman (1999) identified relationships that are based on the extent of resource dependence between a stakeholder and the focal organisation. These resource relationships include stakeholder power, high interdependence, low interdependence and organisation power. In stakeholder power relationships, stakeholders have control over resources, while in high interdependence relationships, organisations and stakeholders depend on one another for resources (Frooman, 1999). In low interdependence relationships, neither the organisation nor the stakeholder depends on the other for resources while in an organisation power relationship, the organisation does not depend on the stakeholder for resources (Frooman, 1999).

A number of previous studies have used Frooman's model, (Elijido-Ten et al., 2010; Hendry, 2005; Rowley \& Moldoveau, 2003; Tsai et al., 2005) including in sport management (Heffernan \& O’Brien, 2010; Xue \& Mason, 2017). However, some critics have highlighted weaknesses regarding the use of this model. For instance, Hendry (2005) pointed out that the model fails to account for alliance formation among stakeholders. Additionally, Tsai et al. (2005) observed that resource dependencies alone cannot be used to determine stakeholder influence strategies. Accounting for these weaknesses, Heffernan and O’Brien (2010) 
suggested that Frooman's model could be used to develop heuristics that broaden understanding on how stakeholders use influence strategies.

To mitigate against the weaknesses of Frooman's model, it is used in conjunction with Mitchell et al.'s (1997) framework, enabling a complementary insight into the behaviour of stakeholders. Stakeholders will firstly be identified using the power, legitimacy and urgency framework, and secondly influence strategies used by stakeholders to affect the PM process will be established. What is important is to draw attention to PM, the crux of this study. To that end stakeholder influence and performance management are presented in the next section of the literature review.

\section{Stakeholder influence and performance management}

The satisfaction of stakeholders has consistently been identified in literature as a determinant for measuring organisational performance among sport organisations (Bayle \& Madella 2002; O’Boyle \& Hassan, 2014; Shilbury \& Moore, 2006; Winand et al., 2010). Performance measurement models such as the multiple constituency (Connolly, Conlon \& Deutsch, 1980) and competing values (Quinn \& Rohrbaugh, 1983) approaches are based on the notion that organisational effectiveness is socially constructed and based on the satisfaction of stakeholders.

NSOs depend on a wide array of stakeholders to provide financial resources, human resources and media for exposure. On the other hand, stakeholders may also depend on specific services delivered by NSOs: for example, many stakeholders expect NSOs to provide mass participation and elite sports programs (Papadimitriou \& Taylor, 2000; Parent et al., 2015). Thus, different stakeholders may be interested in how NSOs implement PM stages 
that include goals and objectives setting, processes and activities, performance measurement, feedback and feedforward (Kasale, Winand \& Robinson, 2018). Despite stakeholder interest in the different stages of PM process, how they influence the implementation of these stages remains unknown.

It has been noted that research on the organisational performance of NSOs has been conducted before, however, most of these studies were directed towards performance measurement with a few studies (Bayle \& Robinson, 2007; O’Boyle \& Hassan, 2015) focussed on PM. Furthermore, while some studies acknowledge the role that stakeholders play in performance measurement, (Papadimitriou \& Taylor, 2000; Shilbury \& Moore, 2006) none of the prior studies explore the influence of stakeholders on the stages of PM among NSOs.

With regards to Botswana and Africa, the paucity of research on PM of NSOs compounds the challenge of establishing the influence of stakeholders on PM in this specific geographical context. Nevertheless, some studies conducted in Botswana indicate that PM systems have been adopted by Botswana government to improve the quality of its public service (Marobela, 2008; Mosware, 2011). However, no studies illustrate how PM is implemented by government departments that deal with sport in Botswana and therefore this study provides an opportunity to explore PM of NSOs in a new and distinct geographical context. Additionally, no studies were found in the literature on the influence of stakeholders on NSOs in Botswana. Lindgreen, Swaen and Campbell (2009) explored how stakeholders influenced corporate social responsibility initiatives among organisations in Botswana and Malawi. But while this study offers insight into the behaviour of stakeholders in developing countries, there remains a need to study the behaviour of stakeholders in the context of sport 
and to gain insights on how stakeholders influence the PM of NSOs. More information on Botswana is presented in the next section of this paper as a part of the rationale for the methods used in this study.

\section{METHODS}

\section{Geographical context}

Botswana national teams have been competing at international events since the country's independence in 1966. However, disappointing results prompted the government to set up a commission of inquiry to investigate the poor performance of the country's national teams in 1997 (Kasale, Hollander \& Burnett, 2003; Shehu \& Mokgwathi, 2007). The inquiry identified structural deficiencies in the administration of sport and recommended the implementation of the National Policy on Sports and Recreation to facilitate reforms to the sporting landscape (Shehu \& Mokgwathi, 2007). This led to developments that include the creation of a government ministry responsible for sport, changes to sport legislature, development of sports infrastructure and increased government spending on sport (Bohutsana \& Akpata, 2013). These developments to the sporting landscape in Botswana create an interesting context to study PM of NSOs.

\section{Research design}

As this was exploratory research into PM in NSOs in a unique and previously unresearched context, qualitative research was considered the most appropriate approach. Interviews and focus groups with stakeholders, board members and operational staff were used to explore, explain and understand how different stakeholders influence PM of NSOs, thus ensuring an in-depth and as rich a source of data as possible. Both interviews and focus groups were used as it was considered that these were complementary data sources: Interviews provided face to 
face interaction between the researchers and the respondents, and focus groups facilitated group dynamics enabling participants the freedom to challenge themselves, and to raise and discuss issues pertinent to the study (Cooper \& Schindler, 2013; Creswell \& Creswell, 2017). Questions for the interview and focus group were developed from literature guided by the objectives of the study. Both the interviews and focus groups followed a semi-structured format, allowing participants the flexibility to explore interesting tangents in discussions and enabling unique contributions to the study (Cooper \& Schindler, 2013; Veal, 2005). All discussions were digitally recorded and later transcribed verbatim.

\section{Participants}

Fourteen $(\mathrm{n}=14)$ out of 37 NSOs affiliated to Botswana National Sports Commission (BNSC) - a sports agency that serves as a link between government and the NSOs - were identified to participate in the study. To ensure diversity, the selection of NSOs was based on the categorisation of the BNSC's Affiliates' Empowerment Policy. This policy classifies NSOs based on their geographical spread, national appeal, popularity, level of activity, equity, social responsibility, focus on development, elite sports performance, numerical strength and quality leadership. Further selection was based on whether NSOs were an Olympic or nonOlympic, individual, team, or mixed sport.

Nine $(n=9)$ board members and twelve $(n=12)$ operational staff from the 14 selected NSOs were interviewed. Board members interviewed included presidents, vice presidents and a secretary general, while the operational staff included chief executive officers, an administration manager, a youth team development officer and sports development officers. Furthermore, sixteen $(n=16)$ participants including ten $(n=10)$ board members and six $(n=6)$ operational staff participated in 3 NSO focus groups, with one group comprising of six 
members and two groups made of five members each. Four operational staff members participated in both the interviews and focus groups.

Stakeholders were also interviewed and participated in focus groups. Bayle and Madella's (2002) stakeholder map was used to ensure the inclusion of a wide range of stakeholders in the study. A total of ten $(n=10)$ stakeholders were interviewed including representatives from an international federation, a continental federation, the Ministry of Youth Empowerment, Sports and Culture Development (hereinafter referred to as Ministry), the BNSC, the Botswana National Olympic Committee, the media, sponsors and the community. In addition, fourteen $(n=14)$ stakeholders including coaches, athletes, officials, team and club representatives from the 14 selected NSOs participated in two stakeholder focus groups, each comprising seven $(n=7)$ members. None of the stakeholders participated in both the interviews and the focus groups.

\section{Data collection}

The data was collected in four phases between January and May 2017 and June and July 2018. The use of phases in the data collection exercise, coupled with the semi-structured format for the interviews and focus groups, allowed for previous phases of the data collection exercise to inform subsequent phases, thereby enriching the quality of discussions and hence the data collected. The first phase of the data collection exercise comprised of focus groups for NSO board members and operational staff. Discussions here centred on the type of resources provided by the stakeholders, stakeholder expectations and whether stakeholders used influence strategies on the PM of NSOs. The second phase entailed interviews and focus group meetings with stakeholders. These followed a linked schedule of open-ended questions 
that explored the resources made available to NSOs, stakeholder expectations and whether stakeholders used influence strategies on PM of NSOs.

In the third phase of the data collection exercise, interviews with board members and members of the operational staff were conducted. A standard interview guide encouraged discussion that explored attributes possessed by various stakeholders according to Mitchell et al.'s (1997) framework as well as influence strategies used by stakeholders on the phases of PM process. In the fourth and final phase, transcripts from interviews and focus groups were confirmed with the participants of the study. This allowed for further three follow-up interviews to be conducted with a board member, a member of operational staff and a stakeholder to enable the collection of additional data to fill gaps identified during the data analysis process.

\section{Data analysis}

The data collected from the interviews and focus groups was managed using the NVivo 11 qualitative data analysis software and thematically analysed. The decision to use thematic analysis was based on its advantages of summarizing key features of a large data set (Nowell, Norris, White \& Moules, 2017). To analyse the data, a coding framework was developed deductively from the theoretical framework. Codes that included expectations of the stakeholders, stakeholder power, legitimacy of stakeholder claims, and urgency of stakeholder claims were developed and used to categorise the data to enable the identification of stakeholders according to Mitchell et al.'s (1997) framework. Additionally, codes that included resources provided by stakeholders, organisation power, stakeholder power, resource interdependence, direct pathways, indirect pathways, withholding strategies and 
usage strategies were developed and used to categorise the data for the identification of influence strategies according to Frooman's (1999) model.

The coding framework was used to develop themes that include types of stakeholder, resources made available to NSOs and influence strategies used on PM of NSOs. Moreover, subthemes that include goal and objective setting, processes and activities, performance measurement, feedback and feedforward were also developed as they described the stages of the PM process influenced by stakeholders. Quotations from the data were identified, assessed for commonalities and differences and used to identify and categorise NSO stakeholders according to their salience (Mitchell et al., 1997) and to identify influence strategies that stakeholders use on the PM of NSOs (Frooman, 1997). The results obtained from this process are presented in the next section.

\section{RESULTS}

\section{Stakeholder identification}

Stakeholders were identified according to how board members and operational staff perceived them to possess salience attributes (Mitchell et al., 1997). There were similarities and differences in these perceptions. Board members and operational staff perceived international federations, continental federations, BNSC and Botswana National Olympic Committee to possess all the salience attributes because they enforced affiliation statutes and regulations that required NSO compliance. A board member and an operational staff described the attributes possessed by international and continental federations as follows:

"[...] they have power to revoke our affiliation [... as] they require compliance to rules and regulations [...]” Interviewee board member \#9. 
"[....] their needs and expectations are legitimate ... we are duty bound to respond [...] with urgency” Interviewee operational staff \#6.

Additionally, board members and operational staff perceived sponsors to possess all the salience attributes because they provided NSOs with funding. The funds provided through sponsorships also came with terms of reference that described what sponsors required. Elaborating on this an operational staff member noted that:

"[...] the needs and expectations of the sponsors are stipulated in the terms of reference of the sponsorship [...] NSOs should urgently meet these to continue receiving the sponsorship. [...] because they provide funding, their [claims] are legitimate” Interviewee operational staff \#11.

In other similarities, both groups perceived the Ministry to possess power and legitimacy attributes but not urgency. Furthermore, there was consensus that the community possessed legitimacy attribute because it comprised of members of the public who paid taxes and, as such, their claims on NSOs were legitimate. Additionally, national team players, coaches, umpires and officials were perceived to possess legitimacy and urgency attributes but not power. Describing attributes possessed by the Ministry, interviewees remarked that: "[...] the Ministry provides grants to [NSOs...] they have every right to make demands” Interviewee board member \#7.

“[... the Ministry's] claim is legitimate. [...] we do not deal with the Ministry on a day to day basis and as such we do not really feel the urgency of their requests" Interviewee operational staff \#1. 
The board members and the operational staff had differing perceptions of the attributes possessed by clubs, teams, individual members and the media. Board members perceived clubs, teams and individual members to possess power, legitimacy and urgency attributes, while operational staff members mostly perceived them to possess legitimacy and urgency but not power. Elaborating on these perceptions, a board member and an operational staff member remarked that:

"[Clubs, teams and individual members] depend on [NSOs] to provide services to them [but] power still lies with [NSO]” Interviewee operational staff \#4.

"[...] they have the power to vote us out of office [...] their claims are legitimate because [NSOs] exist to serve their members, [....] their needs and expectations are urgent” Interviewee board member \#2.

Similarly, operational staff believed that the media possessed power and legitimacy attributes while the board members perceived them to possess only power but not legitimacy or urgency attributes. The perceptions of NSO board members and operational staff on the attributes that various stakeholder possessed helped identify stakeholder types according to Mitchell et al.'s (1997) salience model. The different types of stakeholders identified among NSOs in Botswana are discussed next.

\section{Types of NSO stakeholder}

Based on the perceptions of board members and operational staff, NSO stakeholders in Botswana were identified as definitive, dominant, dependent, dormant and discretionary stakeholder types. International federations, continental federations, BNSC, Botswana National Olympic Committee and sponsors were identified as definitive stakeholders because they possessed all the salience attributes. The Ministry was perceived as a dominant stakeholder because it possessed power and legitimacy attributes, while national team 
players, coaches, umpires and officials were perceived as dependent stakeholders because they possessed legitimacy and urgency attributes. The community was identified as a discretionary stakeholder because of the legitimacy attribute it possessed.

In instances where there were differing perceptions on the attributes possessed by stakeholders, inevitably this results in differences in stakeholder identification. For instance, operational staff believed that the media possessed power and legitimacy attributes making them dominant stakeholders while board members perceived them to possess only power, making them dormant stakeholders. These differing perceptions on the media were explained as follows:

"The media has the power to create or destroy [NSOs, their] claim is legitimate because they cover our events using their own resources" Interviewee operational staff \#11.

"[...] the media may have the power, but they do not have any claim to [NSOs] because they need us as much as we need them. [...] They sell their stories using our events and we need the coverage." Interviewee board member \#1.

The board members and operational staff also differed on the attributes possessed by coaches, umpires and officials: identified as dependent stakeholders by operational staff who perceived them to possess power and legitimacy attributes, but as definitive stakeholders by board members who perceived them to possess all the salience attributes.

Following stakeholder identification, there was an additional need to consider how the different type of stakeholders differently influenced NSOs. This is discussed in the next section. 


\section{Influence strategies used by NSO stakeholders}

The results indicate that stakeholders used withholding and usage strategies, directly and indirectly on Botswana NSOs in line with Frooman's (1999) framework. International and continental federations employed usage strategies through direct pathways based on the high interdependence resource relationship they shared with NSOs. The international and continental federations depended on the NSOs to administer sport in their countries, while NSOs depended on their funding for coaches and officials training, equipment and facility development. Describing this high interdependence relationship, an operational staff member noted that:

"[...international and continental federations] provide [NSOs] with resources [and we...] represent their presence in our countries [...]" Interviewee operational staff $\# 5$.

On the other hand, BNSC, Botswana National Olympic Committee and sponsors shared a stakeholder power resource relationship with NSO. These stakeholders had control over the resources - grants, scholarships and sponsorships, and they used withholding strategies through direct influence pathways on NSOs. A board member described influence strategies used by the BNSC as follows:

"[...] when [NSOS] do not meet the needs and expectations of the BNSC, they can lose their funding [ and even...] their affiliation” Interviewee board member \#2. Similarly, Botswana National Olympic Committee and sponsors used withholding strategies to ensure that NSOs complied with their needs and expectations. 
The media and the Ministry also had control over resources and hence had stakeholder power over NSOs. The media controlled the coverage and sponsorship of sporting events while the Ministry controlled grants made available to NSOs. The media employed withholding influence strategies though direct influence pathways confirming their stakeholder power. A representative of the media noted that:

"[...] when we feel [NSOs] are not meeting our expectations, we do not provide media coverage for their events" Interviewee stakeholder \#4.

In contrast, the Ministry employed withholding strategies through indirect pathways where their influence was exerted through the BNSC. A Ministry representative observed that:

"NSOs are independent and we do not influence them [...] we monitor their activities through [the BNSC] who deal with them directly" Interviewee stakeholder \#2.

A high interdependence resource relationship existed between the NSOs and clubs, teams, individual members, national team players, coaches, umpires and officials. These stakeholders depended on the NSOs to facilitate sporting programs for them and the NSOs relied on them to legitimise their existence. These stakeholders employed usage strategies though direct pathways to influence NSOs. A participant in one of the stakeholder focus groups observed that:

“[...] we need [NSOs] to provide good programmes for our athletes, coaches and umpires [...] we participate in all [NSO] activities” Participant \#3 Focus Group Stakeholder 2.

The community and the NSOs shared a low interdependence resource relationship in which they did not depend on each other for resources. Here the community employed usage strategies indirectly, by using a pressure group called Women in Sport Botswana and 
partnerships with the media to influence NSOs. This was described by a community elder who noted that:

“[...] because [NSOs] use public funds, sometimes we [use] pressure groups [...] when we are not satisfied with their performance [....] we have used WASBO [Women in Sport Botswana] in the past so that we could be heard [...] sometimes we use the media [...]” Interviewee stakeholder \#10.

That said there were instances where the community had power over resources. For example, the community has stakeholder power when they provide community facilities to NSOs. In these instances, the community could directly use withholding strategies to grant or deny NSOs access to playing venues and facilities. A community leader recounted that: "[...] we provide [NSOs] with community facilities [...] but that is [...] at our discretion" Interviewee stakeholder \#10.

The results indicate that stakeholders use influence strategies as described by Frooman (1999) on NSO. How the strategies were used to affect the PM process is presented in the following section.

\section{Stakeholder influence on PM process}

The results indicate that NSO stakeholders used withholding and usage strategies, directly and indirectly to affect different stages of the PM process. Table 1 provides an illustration of the types of stakeholders, the resources they provide and the resource relationship between the stakeholders and the NSOs. Table 1 also shows pathways for manipulating the flow of resources and the influence strategies used in the various stages of the PM process.

\{INSERT TABLE 1 HERE\} 
Table 1 illustrates that international and continental federations employed usage strategies in PM stages that include processes and activities, performance measurement, feedback and feedforward. These stakeholders provided funding for NSO programs and activities, and they required reports on their initiatives. A representative of a continental federation remarked that:

"[...] we fund some activities implemented by [NSO ...] we expect them to report on how they used our investment" Interviewee stakeholder \#1.

In contrast, the BNSC used withholding strategies to influence the goal and objective setting, activities, performance measurement, feedback and feedforward stages of the PM process. The goal and objective setting were influenced by the BNSC's demands for alignment of strategic plans. The BNSC also influenced NSO activities through its approval of funding for sanctioned activities. Additionally, the NSOs were expected to report to the BNSC, prompting NSOs to conduct performance measurement against their objectives. The reports submitted to the BNSC also served as feedback and feedforward for NSOs. As described by some board members and operational staff, the BNSC influenced all stages of the PM process:

"The BNSC demands that we align our strategy with the BNSC 2028 " Interviewee board member \#5.

"[...] we have to report all activities that we engage in to the BNSC [.... the BNSC] moderates our activities” Interviewee operational staff \#1.

"[...] we submit activity, annual and financial reports to the BNSC" Interviewee board member \#3. 
Botswana National Olympic Committee and the sponsors influenced the processes and activities, performance measurement, feedback and feedforward stages of the PM process. Providing details on their influence on the stages of the PM process, a sponsor noted that: "we actively participate in [NSO activities] because it is where we market ourselves [...] a report on our funding is important to us" Interviewee stakeholder \#3. Similarly, the media influenced the activities, feedback and feedforward stages of the PM process through providing media coverage for NSO activities and events. Furthermore, their scrutiny of the NSOs ensures more rigour in reporting mechanisms thereby, influencing both performance measurement, feedback and feedforward stages of the PM process.

The Ministry influenced goal and objectives setting, processes and activities, performance measurement, feedback and feedforward stages of the PM process. While the influence was indirect, it was exerted through the BNSC which ensured compliance of NSOs. Clubs, teams, individual members, national team players, coaches, umpires and officials influenced the goals and objectives set, processes and activities, performance measurement, feedback and feedforward stages of the PM process while the community influenced the activities, feedback and feedforward stages.

\section{DISCUSSION}

\section{Salience of NSO stakeholders}

In identifying Botswana NSO stakeholders according to their salience, it was established that international federations, continental federations, BNSC, Botswana National Olympic Committee and sponsors were definitive stakeholders. The BNSC, international federations and continental federations were perceived to possess power because they could revoke the affiliation status of NSOs resulting in the perception of their claims as legitimate and urgent. 
This result is consistent with the findings of Parent and Deephouse (2007) who established that most definitive stakeholders have some form of regulative or legislative means of power. In addition, the BNSC, Botswana National Olympic Committee and sponsors were identified as definitive stakeholders because they provided resources to NSOs. These stakeholders were perceived to possess utilitarian power enabling them to impose their will on NSOs. The resource constrained nature of the environment in Botswana means that resources received from stakeholders become important for NSO survival. In turn NSOs become susceptible to influence from these stakeholders. Moreover, the receipt of resources resulted in NSOs perceiving the claims by BNSC, Botswana National Olympic Committee and sponsors to be legitimate and urgent, consistent with Mitchell et al.'s (1997) framework.

Another stakeholder that provided resources to NSOs was the Ministry. The Ministry was identified as a dominant stakeholder. While it possessed utilitarian power and its claims were perceived to be legitimate because of the grants it provided to NSOs, its claims were not perceived to be urgent. This is because the Ministry interacts with NSOs through the BNSC and hence it could not exert any urgency on these organisations. Other stakeholders including national team players, coaches, umpires and officials were identified as dependent stakeholders while the community was identified as a discretionary stakeholder.

While board members and operational staff agreed on attributes they perceived some stakeholders to possess, they differed on their perception of salience on some stakeholders. Operational staff perceived clubs, teams and individual members as dependent stakeholders, while board members perceived them as definitive stakeholders. Furthermore, the media was perceived as a dominant stakeholder by operational staff but as a dormant stakeholder by board members. This finding confirms Mitchell et al.'s (1997) supposition that the existence 
of each attribute is a matter of multiple perceptions; a constructed reality rather than an objective one. Furthermore, Hautbois et al. (2012) also found that the salience of the stakeholders and the attributes they possessed varied according to the various cases that they studied.

The most common attribute possessed by NSO stakeholders as perceived by the board and the operational staff was legitimacy. While this result is contrary to Parent and Deephouse (2007) who found power to be the most common attribute, this finding further confirms Mitchell et al.'s (1997) and Hautbois et al.'s (2012) suppositions that salience depends on a constructed reality. Importantly, the salience of the NSO stakeholders in a developing country like Botswana is likely to differ from the salience of the NSO stakeholders from other countries, because of how board members and operational staff perceive stakeholders and the attributes they possess. Further research could usefully consider a comparative analysis between the salience of NSO stakeholders from different economies and cultures to determine if identifying stakeholders differently influences how they will affect organisational processes.

\section{Stakeholders' influence and PM of NSOs}

NSO stakeholders employed withholding and usage strategies to influence the various stages of the PM process. The PM stages influenced depended on the resource relationship between the NSO and the stakeholder, and whether they interacted during the implementation of the stage. Stakeholders such as the BNSC, clubs, teams, individual members, the Ministry, national team players, coaches, umpires and officials used influence strategies on all stages of the PM process because they are involved in their implementation. For instance, the clubs, teams and individual members were involved in the goal setting process as they participated 
in the general meetings where NSO goals were set and reviewed. Furthermore, they are key actors in the implementation of activities that the NSO engages in and they can effect changes to organisational processes through their general meetings. Additionally, these stakeholders are involved in performance measurement processes as it is their activities that are measured, and they are affected by the feedback and feedforward which they should use to improve the implementation of their future activities.

Stakeholders that were not involved in the implementation of some stages of the PM process could not use influence strategies on those stages. For instance, international federations and continental federations, Botswana National Olympic Committee, sponsors, media and community could not use influence strategies on the goals and objectives set by the NSOs because they did not participate in the strategy formulation process. While some of these stakeholders were invited to NSO general meetings, they did not participate in the deliberations and could not influence the goals and objectives set. The NSOs may consider the needs and expectations of these stakeholders when they set their goals and objectives (Parent et al., 2015) but these stakeholders do not influence the process because they are not actively involved in it. Similarly, the media and the community did not use influence strategies on performance measurement processes as they did not participate in them.

The BNSC employed withholding influence strategies to affect all stages of the PM process because they controlled resources, and hence had stakeholder power. Consequently, they influenced goal and objective setting and activities stages by demanding the alignment of NSO and BNSC strategies and ensuring that they sanctioned the activities implemented. Furthermore, the BNSC expected NSOs to report on all activities they engage in and work towards improving their performance in future. When NSOs failed to meet the needs and 
expectations of the BNSC, they stood to lose their grant or have their affiliation revoked. The Ministry also employed withholding strategies on all stages of the PM process because it controlled the resources and grants made available to NSOs. However, the influence pathway that it used was indirect because it depended on the BNSC to interact with the NSOs. The BNSC and the Ministry were the only two stakeholders that used withholding influence strategies on all stages of the PM process and as a result had the most influence on the implementation of the process among NSOs. This could be because the grant funding made available to NSOs formed a large part of their budget.

This view was shared by many board members and operational staff. Based on this view, it can be argued that the Ministry through the BNSC is the key player in influencing how PM is implemented by Botswana NSOs. The government's drive for improvements to the performance of national athletes and teams at international competitions (Shehu \& Mokgwathi, 2007) could offer an explanation to this influence. This result is particularly relevant in a Botswana context where the grant from the Ministry forms the largest part of NSOs budgets. Further research could establish how the government influences the implementation of PM among NSOs in contexts where these organisations have access to a wider range of resource streams.

Botswana National Olympic Committee, sponsors, media and the community are other stakeholders that used withholding strategies to influence stages of the PM process in their interaction with NSOs. For instance, the sponsors could withhold their sponsorship, the media their coverage of sport events, and the community could deny NSOs access to community facilities. These stakeholders used influence strategies on processes and activities, performance measurement, feedback and feedforward stages of the PM process. These results 
indicate that where a stakeholder has control over resources, they may use strategies to influence focal organisations. This result confirms Frooman's (1999) beliefs and the findings of Heffernan and O'Brien (2010) and Xue and Mason (2017), that control over resources gives a stakeholder power to influence the behaviour of the focal organisation. For NSOs in Botswana where resources are scarce because the government is required to deal with more pressing matters such the HIV/Aids pandemic and other health concerns, inevitably fewer resources are available for sport (Chappell, 2004). In addition, as a country with a small population, Botswana is unable to attract big multi-national corporations like its neighbour South Africa as its markets are considered too small. This leads to fewer corporate sponsors and limited access to what could otherwise be a lucrative resource stream for NSOs. These factors help explain the reasons Botswana NSOs are susceptible to influence that results from withholding resources. By meeting their resource needs, organisational and PM processes of NSOs in Botswana are easily influenced by those stakeholders who control resources.

It was also established that in cases where a stakeholder such as the community did not have control over resources, indirect pathways were used by reliance on a pressure group and partnerships with the media to influence stages of the PM process. This is consistent with De Bakker and Den Hond's (2008) finding that a stakeholder can exert influence on a focal organisation by forging alliances with other stakeholders. This finding is further contrary to Hendry (2005) who noted that Frooman's (1999) model could not account for alliance forming behaviours among stakeholders.

Clubs, teams, individual members, national team players, coaches, umpires and technical staff also employed usage influence strategies on all stages of the PM process as they were 
involved in their implementation. This was due to a high interdependence resource relationship between the NSOs and these stakeholders.

\section{CONCLUSION}

Drawing on the established frameworks and models of Mitchell et al. (1997) and Frooman (1999), this research demonstrates that different stakeholder can use different influence strategies dependent on the stages of the PM process that they are involved in. It was also found that stakeholders who contributed the largest share of resources to NSOs were key players as they used withholding strategies to influence all stages of the PM process. Additionally, stakeholders that shared a high interdependence resource relationship with NSOs primarily employed usage strategies throughout the stages of the PM process.

As the study of PM of NSOs evolves, further research could empirically test the relationship between stakeholders, resources, organisational processes and the PM of NSOs. Theoretical development building on stakeholder, resource dependence, institutional, and contingency theories may provide a base to explore the role that stakeholders play in the development and use of PM systems among NSOs. Furthermore, how the NSOs' operational environment is affected by the influence of stakeholders and the influence strategies they use, provides avenues for future research, as does the role that individuals within NSOs play because of stakeholder influences.

This study contributes to sport management literature by demonstrating how stakeholders with different resource relationships with NSOs differently influence the implementation of the stages of PM process. The study provides insights on PM of NSOs in the context of a developing African country, thus enriching our understanding of how stakeholders from 
different geographical contexts influence organisational processes. The study has practical utility because it informs sport managers on how stakeholders use influence strategies on PM. This information is useful to sport managers as they can facilitate organisational processes that account for stakeholder influences, thereby ensuring the satisfaction of their multiple stakeholders and improved service delivery. 


\section{REFERENCES}

Anagnostopoulos, C. (2011). Stakeholder management in Greek professional football: identification and salience. Soccer \& Society, 12(2), 249-264.

Babiak, K. (2007). Determinants of interorganizational relationships: The case of a Canadian nonprofit sport organization. Journal of Sport Management, 21(3), 338-376.

Bayle, E., \& Madella, A. (2002). Development of a taxonomy of performance for national sport organizations. European Journal of Sport Science, 2(2), 1-21.

Bayle, E. \& Robinson, L. (2007). A framework for understanding the performance of national governing bodies of sport, European Sport Management Quarterly, (7)3, 249-268.

Braun, V., \& Clarke, V. (2006). Using thematic analysis in psychology. Qualitative Research in Psychology, 3(2), 77-101.

Bititci, U.S., Carrie, A.S. and McDevitt, L. (1997). Integrated performance measurement systems: a development guide, International Journal of Operations \& Production Management, 17(5), 522-534.

Bohutsana, B., \& Akpata, D. (2013). Marketing sports facilities: perspectives from Botswana. The ICHPER-SD Journal of Research in Health, Physical Education, Recreation, Sport \& Dance, 8(2), 26-32.

Chappell R (2004) Sport development in Botswana. The Sport Journal 7(2). Available at: http:// www.thesportjournal.org/article/sports-development-botswana-africa, accessed 04 March 2019.

Chelladurai, P., \& Haggerty, T.R. (1991). Measures of organizational effectiveness of Canadian national sport organizations. Canadian Journal of Sport Sciences (Journal Canadien des Sciences du Sport), 16(2), 126-133. 
Clarkson, M. 1994. A risk-based model of stakeholder theory. Proceedings of the Second Toronto Conference on Stakeholder Theory. Toronto: Centre for Corporate Social Performance and Ethics, University of Toronto.

Clarkson, M.E. (1995). A stakeholder framework for analyzing and evaluating corporate social performance. Academy of Management Review, 20(1), 92-117.

Connolly, T., Conlon, E.J., \& Deutsch, S.J. (1980). Organizational effectiveness: A multipleconstituency approach. Academy of Management Review, 5(2), 211-218.

Cooper, D.R. \& Schindler, P. (2013). Business Research Methods. McGraw-Hill Education. New York.

Creswell, J.W. \& Creswell J.D. (2017). Qualitative, Quantitative and Mixed Methods Approaches. Sage Publications. Thousand Oaks, California.

De Bakker, F.G., \& Den Hond, F. (2008). Introducing the politics of stakeholder influence: A review essay. Business \& Society, 47(1), 8-20.

Eberendu, A.C., Akpana, E.O., Uban, E.C. \& Okorocha, K.A. (2017). Analysis of stakeholder influence: Perceptions of software engineering projects in Nigeria. Management Sciences and Engineering 11(2), 1-8.

Elijido-Ten, E., Kloot, L., \& Clarkson, P. (2010). Extending the application of stakeholder influence strategies to environmental disclosures: An exploratory study from a developing country. Accounting, Auditing \& Accountability Journal, 23(8), 10321059.

Ferreira, A. and Otley, D. (2009). The design and use of performance management systems: An extended framework for analysis, Management Accounting Research, 20(4), 263 282.

Freeman, R.E. (1984). Strategic Management: A Stakeholder Approach, Pitman, Boston. 
Frooman, J. (1999). Stakeholder influence strategies. Academy of management review, 24(2), 191-205.

Hautbois, C., Parent, M.M., \& Séguin, B. (2012). How to win a bid for major sporting events? A stakeholder analysis of the 2018 Olympic Winter Games French bid. Sport Management Review, 15(3), 263-275.

Heffernan, J. \& O’Brien, D. (2010). Stakeholder influence strategies in bidding for a professional sport franchise license. Sport Management Review, 13(3), 255-268.

Hendry, J.R. (2005). Stakeholder influence strategies: An empirical exploration. Journal of Business Ethics, 61(1), 79-99.

Holt, M. (2007). The ownership and control of Elite club competition in European football. Soccer \& Society, 8(1), 50-67.

Kasale, L.L., Burnett, C., \& Hollander, W.J. (2003). Analysis of corporate sponsorship among super league football teams in Botswana. African Journal for Physical Activity and Health Sciences, 9(3), 59-67.

Kasale, L.L., Winand, M., \& Robinson, L. (2018). Performance management of National Sports Organisations: a holistic theoretical model. Sport, Business and Management: An International Journal, 8(5), 469-491.

Laplume, A.O., Sonpar, K., \& Litz, R.A. (2008). Stakeholder theory: Reviewing a theory that moves us. Journal of Management, 34(6), 1152-1189.

Lindgreen, A., Swaen, V., \& Campbell, T.T. (2009). Corporate social responsibility practices in developing and transitional countries: Botswana and Malawi. Journal of Business Ethics, 90(3), 429-440.

Madella, A., Bayle, E. and Tome, J. (2005). The organisational performance of national swimming federations in Mediterranean countries: A comparative approach, European Journal of Sport Science, 5(4), 207-220. 
Marobela, M. (2008). New public management and the corporatisation of the public sector in peripheral capitalist countries. International Journal of Social Economics, 35(6), 423434.

Miragaia, D. A. M., Ferreira, J., \& Carreira, A. (2014). Do stakeholders matter in strategic decision making of a sports organization? Revista de Administração de Empresas, 54(6), 647-658.

Mitchell, R.K., Agle, B.R., \& Wood, D.J. (1997). Toward a theory of stakeholder identification and salience: Defining the principle of who and what really counts. Academy of Management Review, 22(4), 853-886.

Mosware, R.B. (2011). An investigation of attitudes and challenges faced by teachers in the implementation of performance management system in secondary school in Botswana. (Doctoral dissertation, University of North West, South Africa). Retrieved from https://repository.nwu.ac.za/bitstream/handle/ 10394/15787 /Mosware_RB.pdf? sequence $=1$

Nowell, L.S., Norris, J.M., White, D.E., \& Moules, N.J. (2017). Thematic analysis: Striving to meet the trustworthiness criteria. International Journal of Qualitative Methods, 16(1), DOI: 1609406917733847.

Nowy, T., Wicker, P., Feiler, S., \& Breuer, C. (2015). Organizational performance of nonprofit and for-profit sport organizations. European Sport Management Quarterly, $15(2), 155-175$.

O’Boyle, I. (2015). Developing a performance management framework for a national sport organisation. Sport Management Review, 18(2), 308-316.

O’Boyle, I., \& Hassan, D. (2014). Performance management and measurement in nationallevel non-profit sport organisations, European Sport Management Quarterly, 14(3), 299-314. 
O'Boyle, I., \& Hassan, D. (2015). Applying performance management practices within nonprofit sport organisations: a case study of New Zealand. International Journal of Sport Management, 16(2), 1-24.

Olander, S. (2007). Stakeholder impact analysis in construction project management. Construction Management and Economics. 25(3), 277-287.

Papadimitriou, D., \& Taylor, P. (2000). Organisational effectiveness of Hellenic national sports organisations: A multiple constituency approach, Sport Management Review, 3(1), 23-46.

Parent, M.M., \& Deephouse, D.L. (2007). A case study of stakeholder identification and prioritization by managers. Journal of Business Ethics, 75(1), 1-23.

Parent, M.M., Kristiansen, E., Skille, E.Å., \& Hanstad, D.V. (2015). The sustainability of the Youth Olympic Games: Stakeholder networks and institutional perspectives, International Review for the Sociology of Sport, 50(3), 326-348.

Parent, M.M., \& Séguin, B. (2007). Factors that led to the drowning of a world championship organizing committee: A stakeholder approach. European Sport Management Quarterly, 7(2), 187-212.

Perck, J., Van Hoecke, J., Westerbeek, H., \& Breesch, D. (2016). Organisational change in local sport clubs: the case of Flemish gymnastics clubs, Sport, Business and Management: An International Journal, 6(2) 158-181.

Pfeffer, J. \& Salancik, G.B. (1978). The External Control of Organizations, Harper and Row, New York.

Quinn, R.E., \& Rohrbaugh, J. (1983). A spatial model of effectiveness criteria: Towards a competing values approach to organizational analysis. Management Science, 29(3), 363-377. 
Rowley, T.I., \& Moldoveanu, M. (2003). When will stakeholder groups act? An interest-and identity-based model of stakeholder group mobilization. Academy of Management Review, 28(2), 204-219.

Shehu, J., \& Mokgwathi, M.M. (2007). A discourse analysis of the National Sport and Recreation Policy for Botswana. Sport, Education and Society, 12(2), 193-210. Shilbury, D. \& Moore, K.A. (2006). A study of organizational effectiveness for national Olympic sporting organizations. Nonprofit and Voluntary Sector Quarterly, 35(1), 538.

Solntsev, I., \& Osokin, N. (2018). Designing a performance measurement framework for regional networks of national sport organisations: evidence from Russian football. Managing Sport and Leisure, 17, 1-21.

Sotiriadou, K. (2009). The Australian sport system and its stakeholders: development of cooperative relationships. Sport in Society, 12(7), 842-860.

Tsai, P.C., Yeh, C.R., Wu, S.L., \& Huang, I.C. (2005). An empirical test of stakeholder influence strategy models: Evidence from business downsizing in Taiwan. The International Journal of Human Resource Management, 16(10), 1862-1885.

Veal, A.J. (2005). Business Research Methods: A Managerial Approach. Addison-Wesley. Melbourne.

Wicker, P. \& Breuer, C. (2011). Scarcity of resources in German non-profit sport clubs, Sport Management Review, 14(2), 188-201.

Wicker, P., Vos, S., Scheerder, J., \& Breuer, C. (2013). The link between resource problems and interorganisational relationships: a quantitative study of Western European sport clubs. Managing Leisure, 18(1), 31-45. 
Winand, M., Rihoux, B., Robinson, L. \& Zintz, T. (2013). Pathways to high performance: a Qualitative Comparative Analysis of sport governing bodies. Non Profit and Voluntary Sector Quarterly, 42(4), 739-762.

Winand, M., Vos, S., Claessens, M., Thibaut, E. \& Scheerder, J. (2014), A unified model of non-profit sport organizations performance: perspectives from the literature, Managing Leisure, 19(2), 121-150.

Winand, M., Zintz, T., Bayle, E. and Robinson, L. (2010), Organizational performance of Olympic sport governing bodies: dealing with measurement and priorities, Managing Leisure, 15(4), 279-307.

Xue, H., \& Mason, D. (2017). Stakeholder influence strategies in China: the case of Beijing's MasterCard Center. International Journal of Sports Marketing and Sponsorship, $18(4), 400-417$. 
Table 1: Stakeholder identification, influence strategies and stages of the PM process

\begin{tabular}{|c|c|c|c|c|c|c|}
\hline \multirow[t]{2}{*}{ Stakeholder types } & \multirow[t]{2}{*}{ Stakeholder } & \multirow[t]{2}{*}{ Resources } & \multicolumn{4}{|c|}{ Influence strategy } \\
\hline & & & $\begin{array}{l}\text { Goal \& objective } \\
\text { setting }\end{array}$ & $\begin{array}{l}\text { Processes \& } \\
\text { activities }\end{array}$ & $\begin{array}{l}\text { Performance } \\
\text { measurement }\end{array}$ & $\begin{array}{l}\text { Feedback \& } \\
\text { Feedforward }\end{array}$ \\
\hline \multirow[t]{6}{*}{ Definitive stakeholders } & International federations & $\begin{array}{l}\text { Scholarships } \\
\text { Facility development } \\
\text { Equipment }\end{array}$ & & $\begin{array}{l}\text { HI, Direct } \\
\text { Usage }\end{array}$ & $\begin{array}{l}\text { HI, Direct } \\
\text { Usage }\end{array}$ & $\begin{array}{l}\text { HI, Direct } \\
\text { Usage }\end{array}$ \\
\hline & Continental federations & $\begin{array}{l}\text { Scholarships } \\
\text { Facility development } \\
\text { Equipment }\end{array}$ & & $\begin{array}{l}\text { HI, Direct } \\
\text { Usage }\end{array}$ & $\begin{array}{l}\text { HI, Direct } \\
\text { Usage }\end{array}$ & $\begin{array}{l}\text { HI, Direct } \\
\text { Usage }\end{array}$ \\
\hline & $\begin{array}{l}\text { Botswana National Sports } \\
\text { Commission }\end{array}$ & Government grants & $\begin{array}{l}\text { SP, Direct } \\
\text { Withholding }\end{array}$ & $\begin{array}{l}\text { SP, Direct } \\
\text { Withholding }\end{array}$ & $\begin{array}{l}\text { SP, Direct } \\
\text { Withholding }\end{array}$ & $\begin{array}{l}\text { SP, Direct } \\
\text { Withholding }\end{array}$ \\
\hline & $\begin{array}{l}\text { Botswana National } \\
\text { Olympic Committee }\end{array}$ & Scholarships & & $\begin{array}{l}\text { SP, Direct } \\
\text { Withholding }\end{array}$ & $\begin{array}{l}\text { SP Direct } \\
\text { Withholding }\end{array}$ & $\begin{array}{l}\text { SP, Direct } \\
\text { Withholding }\end{array}$ \\
\hline & Sponsors & Sponsorships & & $\begin{array}{l}\text { SP, Direct } \\
\text { Withholding }\end{array}$ & $\begin{array}{l}\text { SP, Direct } \\
\text { Withholding }\end{array}$ & $\begin{array}{l}\text { SP, Direct } \\
\text { Withholding }\end{array}$ \\
\hline & $\begin{array}{l}\text { Clubs, Teams, Individual } \\
\text { members (BM) }\end{array}$ & Membership fees & $\begin{array}{l}\text { HI, Direct } \\
\text { Usage }\end{array}$ & $\begin{array}{l}\text { HI, Direct } \\
\text { Usage }\end{array}$ & $\begin{array}{l}\text { HI, Direct } \\
\text { Usage }\end{array}$ & $\begin{array}{l}\text { HI, Direct } \\
\text { Usage }\end{array}$ \\
\hline \multirow[t]{2}{*}{ Dominant stakeholders } & $\begin{array}{l}\text { Ministry, Youth Sports \& } \\
\text { Culture }\end{array}$ & Grants & $\begin{array}{l}\text { SP, Indirect } \\
\text { Withholding }\end{array}$ & $\begin{array}{l}\text { SP, Indirect } \\
\text { Withholding }\end{array}$ & $\begin{array}{l}\text { SP, Indirect } \\
\text { Withholding }\end{array}$ & $\begin{array}{l}\text { SP, Indirect } \\
\text { Withholding }\end{array}$ \\
\hline & Media (OP) & $\begin{array}{l}\text { Media coverage } \\
\text { Marketing }\end{array}$ & & $\begin{array}{l}\text { SP, Direct } \\
\text { Withholding }\end{array}$ & & $\begin{array}{l}\text { SP, Direct } \\
\text { Withholding }\end{array}$ \\
\hline \multirow[t]{3}{*}{ Dependent stakeholders } & $\begin{array}{l}\text { Clubs, Teams, Individual } \\
\text { members (OP) }\end{array}$ & Membership fees & $\begin{array}{l}\text { HI, Direct } \\
\text { Usage }\end{array}$ & $\begin{array}{l}\text { HI, Direct } \\
\text { Usage }\end{array}$ & $\begin{array}{l}\text { HI, Direct } \\
\text { Usage }\end{array}$ & $\begin{array}{l}\text { HI, Direct } \\
\text { Usage }\end{array}$ \\
\hline & National Team Players & Elite athlete services & $\begin{array}{l}\text { HI, Direct } \\
\text { Usage }\end{array}$ & $\begin{array}{l}\text { HI, Direct } \\
\text { Usage }\end{array}$ & $\begin{array}{l}\text { HI, Direct } \\
\text { Usage }\end{array}$ & $\begin{array}{l}\text { HI, Direct } \\
\text { Usage }\end{array}$ \\
\hline & $\begin{array}{l}\text { Coaches, Umpires, } \\
\text { Technical staff }\end{array}$ & Professional sport services & $\begin{array}{l}\text { HI, Direct } \\
\text { Usage }\end{array}$ & $\begin{array}{l}\text { HI, Direct } \\
\text { Usage }\end{array}$ & $\begin{array}{l}\text { HI, Direct } \\
\text { Usage }\end{array}$ & $\begin{array}{l}\text { HI, Direct } \\
\text { Usage }\end{array}$ \\
\hline Dormant stakeholders & Media (BM) & $\begin{array}{l}\text { Media coverage } \\
\text { Marketing }\end{array}$ & & $\begin{array}{l}\text { SP, Direct } \\
\text { Withholding }\end{array}$ & & $\begin{array}{l}\text { SP, Direct } \\
\text { Withholding }\end{array}$ \\
\hline Discretionary stakeholders & Community & Community facilities & & $\begin{array}{l}\text { SP, Direct } \\
\text { Withholding }\end{array}$ & & $\begin{array}{l}\text { SP, Indirect } \\
\text { Withholding }\end{array}$ \\
\hline
\end{tabular}

Note: BM: Board members; OP: Operational staff; HI: High interdependence; LI: Low interdependence; SP: Stakeholder power 